\title{
CORSIA - CARBON OFFSETTING AND REDUCTION SCHEME FOR INTERNATIONAL AVIATION
}

\section{Miloš Strouhal ${ }^{1 *}$}

${ }^{1}$ Czech Technical University in Prague, Faculty of Transportation Sciences, Prague, Czech Republic

*Corresponding author: Czech Technical University in Prague, Faculty of Transportation Sciences, Horská 3, 12801 Prague, Czech Republic, E-mail: stroumil@fd.cvut.cz

\section{Abstract}

The article discusses the CORSIA - a newly introduced an emission mitigation approach for the global airline industry, developed by the International Civil Aviation Organization (ICAO). It also describes all phases of the project, their analysis and the practical impact of CORSA on aircraft operators. The examples show the operator's costs associated with this project. The mutual coexistence of CORSIA and the EU ETS is also analysed.

\section{Keywords}

CORSIA, EU ETS, Offset Programs, $\mathrm{CO}_{2}$, Emissions, Civil Aviation

\section{Introduction}

The emission reduction is a topical issue that is addressed across industries. Sustainable development - the consistency of economic and social progress with the full preservation of the environment - is the meta which should be achieved if we want to prevent global environmental degradation.

The aviation is committed to meeting its commitments and playing a role in meeting international emission reduction targets globally - through ICAO.

ICAO has agreed on two aspirational goals for the international aviation sector (shown on figure 1):

- $2 \%$ annual fuel efficiency improvement through 2050

- Carbon neutral growth from 2020 onwards (CNG 2020)
ICAO has identified the following areas that can contribute to the attainment of the global aspirational goals:

- Aircraft related technology and standards

- Improved air traffic management and operational improvements

- Development and deployment of sustainable aviation fuel

- CORSIA [1]

\section{New methodology for emission mitigation - CORSIA}

CORSIA - Carbon Offsetting and Reduction Scheme for International Aviation. The scheme introduced by ICAO is a global 


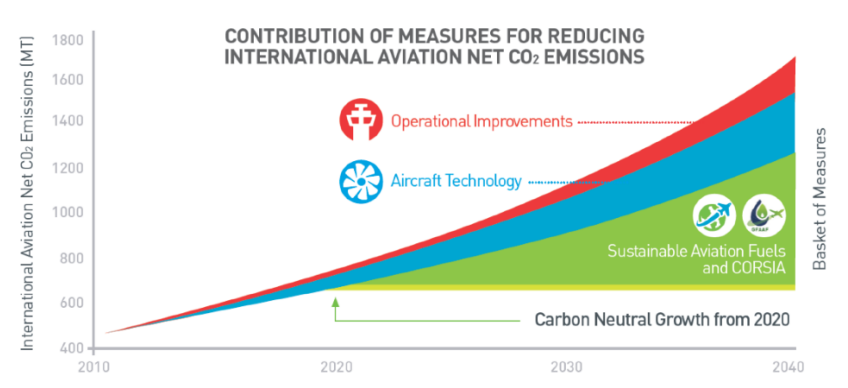

Figure 1. Contribution of Measures For Reducing International Aviation NET $\mathrm{CO}_{2}$ Emissions - Source ICAO

netting mechanism. The aim of CORSIA is to help address each year's increase in total $\mathrm{CO}_{2}$ emissions from international civil aviation.

The First Edition of Annex 16, Volume IV where CORSIA is contained was adopted by the Council of ICAO on 27 June 2018 and became applicable on 1 January 2019 as specified in the Resolution of Adoption. The implementation of CORSIA in Czech Republic is in responsibility of the Ministry of Transport (MoT). This is different from the EU ETS, for which the Ministry of the Environment (MoE) is responsible.

CORSIA has monitoring - baseline period and 3 implementation phases.

\subsection{Baseline Period}

As shown on Figure 2 starting 01 January 2019, all aircraft operators are required to monitor $\mathrm{CO}_{2}$ emissions from international flights (only).

Aircraft operators must to monitor and report its fuel use from international flights to determine its annual $\mathrm{CO}_{2}$ emissions, in accordance with an eligible monitoring method approved by the State to which it is attributed. To simplify the estimation and reporting of $\mathrm{CO}_{2}$ emissions from international flights for operators with low level of activity in fulfilling their monitoring and reporting requirements, ICAO has developed the CORSIA $\mathrm{CO}_{2}$ Estimation and Reporting Tool (CERT). CERT supports aircraft operators in two ways: Estimating $\mathrm{CO}_{2}$ emissions and populating the Emissions Monitoring Plan and Emissions Report templates.

CERT also supports all aircraft operators in determining if their $\mathrm{CO}_{2}$ emissions are under the threshold to be exempt from the CORSIA reporting requirements $(\leq 10000$ tonnes of $\mathrm{CO}_{2}$ annually). Aircraft operators who emit $\geq 500000$ tonnes of $\mathrm{CO}_{2}$ annually in 2019 and 2020 from international flights are not eligible to use CERT to monitor and report emissions and must choose one of the five eligible methods for Fuel Use Monitoring (the five methods are equivalent and there is no hierarchy for selecting a method) (Figure 3). CERT functionality is very similar to the one of Small Emitters Tool used in EU ETS.

Emissions Monitoring Plan - An emissions monitoring plan is collaborative tool between the State and the aircraft operator that identifies the most appropriate manes and meth- ods for $\mathrm{CO}_{2}$ emissions monitoring on and operator - specific basic and facilitates the reporting of required information to the State.

Developing an Emissions Monitoring Plan has three steps as follows:

1. Preparation and Submission - An aircraft operator submits an Emissions Monitoring Plan for the consultation and review by the State to which it is attributed.

2. Review and approval - The State reviews and approves the Emission Monitoring Plan

3. Revisions and updates - An aircraft operator resubmits the Emissions Monitoring Plan for review and approval by the State if a material change is made to the information contained within the Emission Monitoring Plan [1].

After an aircraft operator has monitored its fuel use in accordance with its approved Emissions Monitoring Plan, the $\mathrm{CO}_{2}$ emissions should be calculated from the fuel burn. ICAO CORSIA CERT automatically estimates the $\mathrm{CO}_{2}$ emissions. An aircraft operator using one of the Fuel Use Monitoring Methods should calculate its $\mathrm{CO}_{2}$ emissions using the following equation:

$$
\mathrm{CO}_{2}=\sum M_{f} * F C F_{f}
$$

$\mathrm{CO}_{2}$ Emissions $=$ Mass $(\mathrm{M})$ of fuel $*$ Fuel Conversion Factor (FCF) of given fuel type Fuel Conversion factor:

- $3.16 \mathrm{~kg} \mathrm{CO}_{2} / \mathrm{kg}$ fuel for Jet-A fuel

- $3.10 \mathrm{~kg} \mathrm{CO} / \mathrm{kg}$ fuel for AvGas or Jet-B fuel [1]

\subsection{Implementation Phases}

As shown on table 1 the first part of the implementation is only voluntary (2021-2026) and consist of Pilot phase (20212023) and First phase (2024-2026). The second part is the mandatory and it is named Second phase (2027-2029, 20302032, 2033-2035. Offsetting requirements must be met every 3 years following each compliance cycle).

Aircraft operators must monitor, verify and report their fuel use according to the approved monitoring plan. Their annual emissions offsetting requirements are calculated by the State.

\subsubsection{CORSIA verification of measured values and pro- cess}

The verification of $\mathrm{CO}_{2}$ emissions data in CORSIA is carried out through verification agencies (verifier). Aircraft operators must engage a third party verifier for the verification of its annual emissions report.

The verification is an independent procedure that is used for checking that a product, service, or system meets requirements and specifications and that it fulfills its intended purpose. Verification ensures that the final report submitted to State is satisfactory. Internal pre-verification is recommended. 


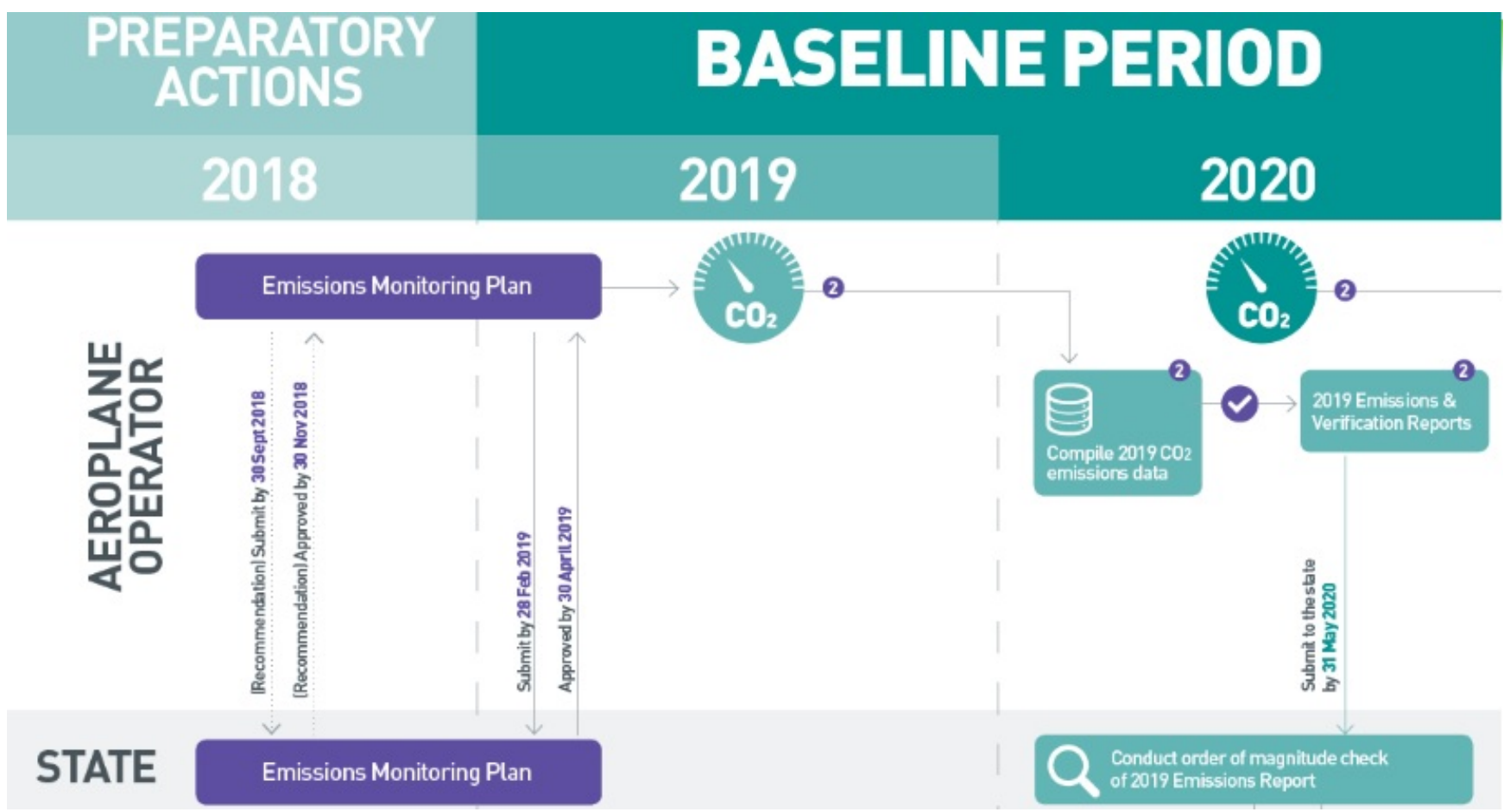

Figure 2. Diagram of baseline period - source ICAO

Table 1. Implementation Phases [1]

\begin{tabular}{|c|c|}
\hline $\begin{array}{l}\text { Pilot phase } \\
2021-2023\end{array}$ & $\begin{array}{l}\text { Voluntary } \\
\text { Baseline: average 2019-2020 } \\
\text { Year offsetting is applied to: } 2020 \text { or given year (states can choosefreely) } \\
\text { Offsetting requirements: } 100 \% \text { sectoral rate }\end{array}$ \\
\hline $\begin{array}{l}\text { First phase } \\
2024-2026\end{array}$ & $\begin{array}{l}\text { Voluntary } \\
\text { Baseline: average } 2019-2020 \\
\text { Year offsetting is applied to: given year } \\
\text { Offsetting requirements: } 100 \% \text { sectoral rate }\end{array}$ \\
\hline $\begin{array}{l}\text { Second Phase } \\
\text { 2027-2035 }\end{array}$ & $\begin{array}{l}\text { Mandatory } \\
\text { Baseline: average 2019-2020 } \\
\text { Year offsetting is applied to: given year } \\
\text { Offsetting requirements: at least } 20 \% \text { individual rate from } 2030 \text {, at least } 70 \% \text { from } 2033\end{array}$ \\
\hline
\end{tabular}

An aircraft operator must engage a third-party accredited verifier [1].

\section{CORSIA offsetting requirements (Figure 4)}

1. The State calculates the offsetting requirements attributed to an aircraft operator

Operator's annual emissions $\mathrm{x}$ Growth Factor $=\mathrm{CO}_{2}$ offset requirements

In a given year from 2021, the Growth Factor is the percent increase in the amount of emissions from the baseline, and is calculated by ICAO. The Growth Factor changes every year taking into account both the sector's and the individual operator's emissions growth.
2. The operator reports the use of sustainable aviation fuels (SAF) for a 3-year compliance period.

3. The State acounts for the benefits from the use of SAF and informs the operator of its final $\mathrm{CO}_{2}$ offsetting requirements for a 3-year compliance period.

4. The operator purchases and cancels eligible emissions units equivalent to its final $\mathrm{CO}_{2}$ offsetting requirements for the compliance period.

- Generate: Emissions reduction projects generate emissions units.

- Purchase: Emissions units are purchased in carbon markets on e per-tonne basic

$$
1 \text { Emissions Unit }=1 \text { Tonne of } \mathrm{CO}_{2}=1 \text { Offset }
$$




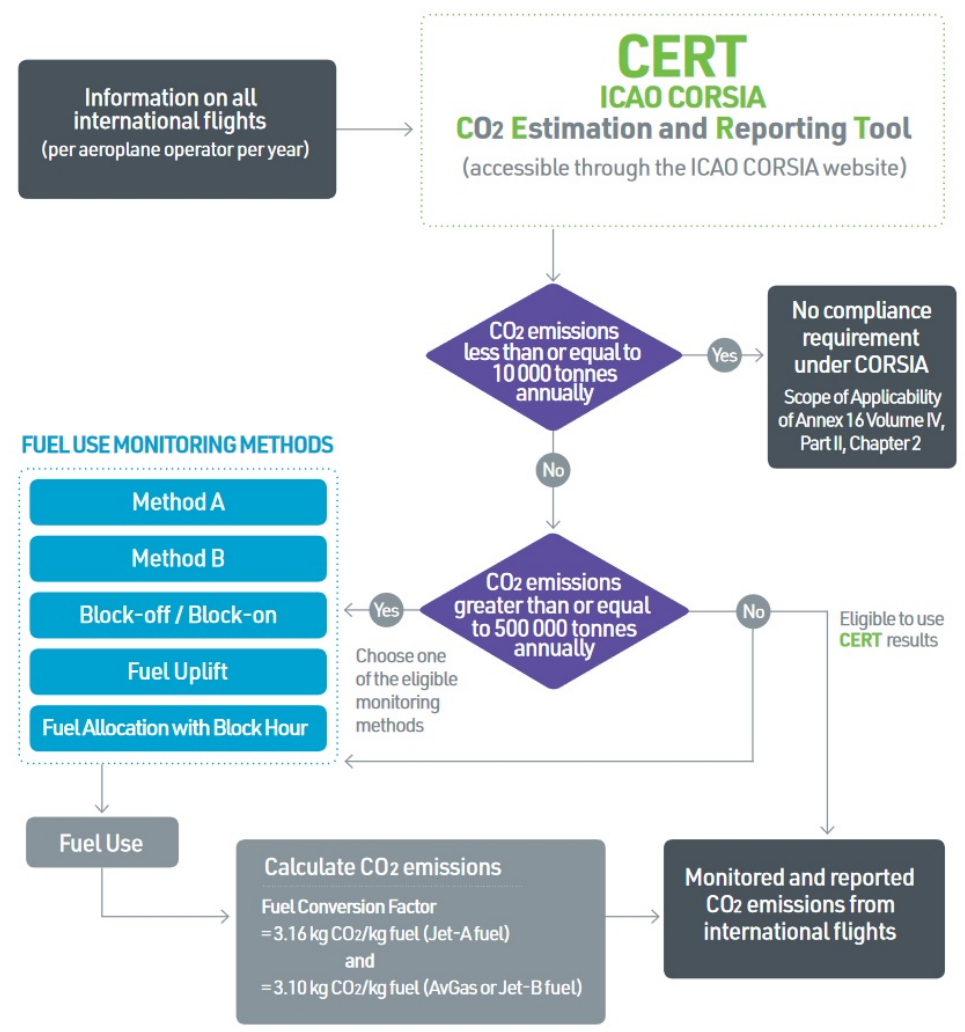

Figure 3. Decision tree diagram for emissions monitoring options (2019-2020) [2]

- Cancel: Operators cancel CORSIA eligible emissions units. Cancellation takes place within a registry desingated by a CORSIA Eligible Emissions Unit Program.

- Publish: Operators request each CORSIA Eligible Emissions Unit Program Registry to make visible the cancelation information on the registry's public website.

5. The operator provides a verified Emissions Units Cancelation Report to the State, who checks the Report and informs ICAO [1].

Emissions Units (offsets) are representing emissions reduction generated by the implementation of projects elsewhere. They are generated by each project/mechanism/scheme. Generation of Emissions Units is calculated as the difference between emissions production at business-as-usual scenario and after implementation of the reduction project.

Emissions reductions projects generate emissions units that are traded on a Carbon Market in the same way as other commodities. Emissions units are traded on a per-tonne basis. The supply and demand of the emission units will affect the prices of units.

\section{Offsetting time frame:}

2019 - 2020 - No offsetting requirements, all States are 'participating'
2021 - 2026 - Voluntary participation

2027 - 2035 - Mandatory participation for States with high aviation activity

\section{Impacts of Corsia on Aircraft Operators}

A similar system as CORSIA is currently in place in the EU EU emissions trading system (EU ETS) - as the cornerstone of EU climate change policy and its key tool for cost-effective greenhouse gas reduction. This European system is based on a principle and rules other than CORSIA. Scope of EU ETS remains unchanged until 2023. New monitoring plan template common for EU ETS and CORSIA is not available now which means uncertainty for European aircraft operators whether the systems will not be duplicated for one operation. This would significantly deteriorate the business of mainly European aircraft operators compared to operators from other parts of the world. Another problem is cost prediction. As with the EU ETS, it will be difficult within CORSIA to estimate the cost of offset programs over a specified period (every 3 years).

The EU ETS has an annual cycle - the amount of $\mathrm{CO}_{2}$ released is calculated and a report is formed. The report is then verificated by a verification agency. At the beginning of each year, the aircraft operator must submit a report for the previous year on the basis of which the quantity of emission allowances needed is determined. By the end of April the carrier must have allowances in the account and surrender 


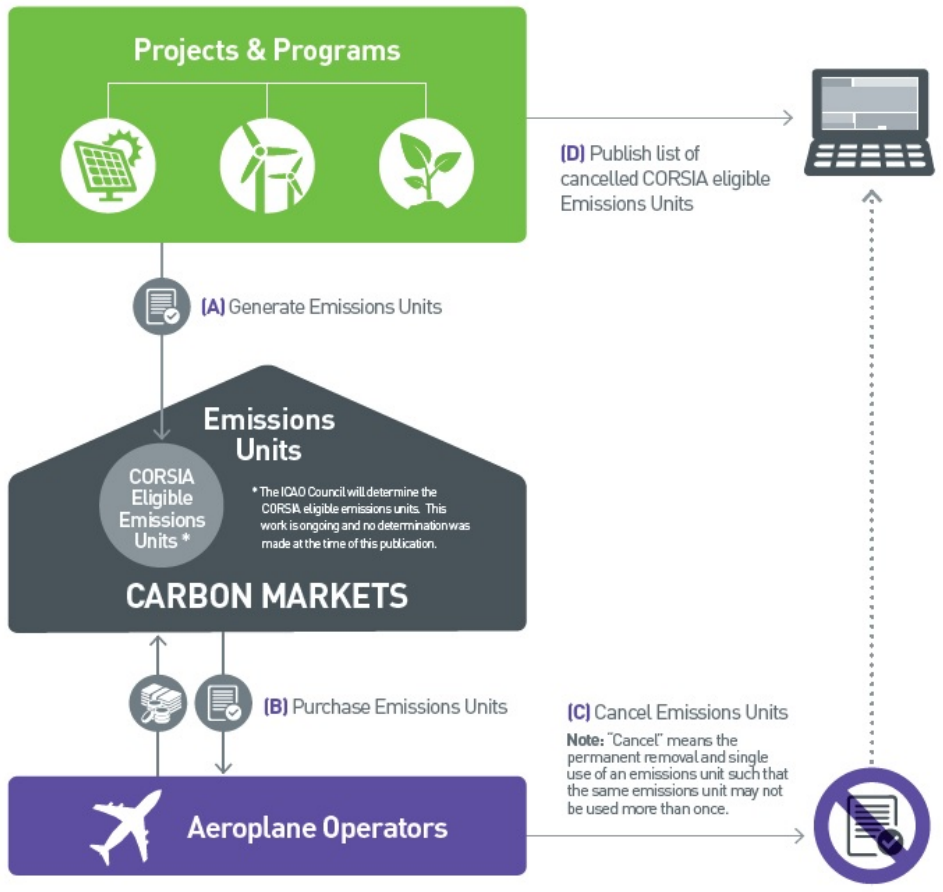

Figure 4. Offsetting requirements steps according to draft CORSIA SARPs [2]

them. This process is more difficult in Corsia. Since 2021 a three-year cycles are set. The determining baseline is set during years 2019 and 2020. For period 2021-2023 aircraft operators must report data on the increase in $\mathrm{CO}_{2}$ compared to baseline. Then the data have to be verified and send to ICAO, which will process it during one year. The amount of offsets that will have to be purchased will be known in year 2025. This procedure is then repeated regularly until 2035.

If aircraft operators do not continually make financial reserves to cover these costs, they may have trouble paying their liabilities (financial involvement in offset programs) at a time when it is necessary to participate in CORSIA offset programs.

Different rules are set for new aircraft operators that will be established after 2020. These aiplane operators will have set no baseline. So they have the rule that they will pay nothing for emissions for the first three years and that they will pay for all emissions emitted after these three years. Not just an increase over baseline, as is the case with current carriers, who will determine baseline based on the amount of emissions emitted in 2019-2020. Thus, emerging aircraft operators will have a disadvantage over already existing ones [1].

Examples of current cost for emission allowances and and forward-looking costs for them.

Cost of emission allowances per hour of flight (B738):

3.15 tonnes of $\mathrm{CO}_{2}$ are released from one tonne of aircraft B738 burnt fuel. An average of 2.45 tonnes of fuel is consumed per flight hour [3]. Than 7.7 tons of $\mathrm{CO}_{2}$ are emitted per hour of flight. The price of the allowance is now around
25EUR per ton of $\mathrm{CO}_{2}$ [4]. The cost of one hour of flight is 193EUR only on emission allowances now.

Comparison of emission allowance costs with fuel price (B738):

Average fuel price is now 750USD per ton. The costs for emission allowances are now about 78EUR per ton of fuel $=$ about 87USD. Over the past 3 years, the price of emission allowances has risen 5x [4]. Now the cost of emission allowances is $1 / 7$ of the fuel price. If emission allowances continue to rise at this rate, the cost of emission allowances may reach $1 / 2$ of fuel prices in a few years. It is a significant cost which have to be eflected in the price of the air tickets.

\section{Conclusion}

Based on current calculations, CORSIA would be "cheaper“ for European aircraft operators compared to the EU ETS calculated from the offsets which are currently on the market. Since the EU ETS is a financially beneficial program for the $\mathrm{EU}$, this system is not expected to be completely abolished. This system is used to finance environmental programs in individual EU countries.

CORSIA has a lot of questions at this time. For example, whether there will be enough approved offset programs or whether the verification of offset programs will not be misused in countries with poor internal control.

Of course, there is a need for a system as CORSIA that starts addressing the amount of increased $\mathrm{CO}_{2}$ emitted not only in EU but in the worldwide. Only technological advances 
(eg in the development of engines with lower fuel consumption) will not halt expected $\mathrm{CO}_{2}$ growth.

The European Commission is now waiting for the introduction of CORSIA. The system will then evaluate and probably make some changes to the EU ETS.

\section{References}

[1] CORSIA training course 2019. ICAO, 2019.

[2] Carbon offsetting and reduction scheme for international aviation (corsia) $/ /$. URL https://www.icao.int/environmentalprotection/CORSIA/Pages/default.aspx.

[3] Internal information materials of Smartwings airlines Average fleet consumption 2018/2019. Smartwings Group, a. s., 2019.

[4] Co2 european emission allowances price today. Business Insider. URL https://markets. businessinsider.com/commodities/co2european-emission-allowances. 